\title{
Garantía de audiencia-debido proceso. Transgresión del derecho humano al importador en el procedimiento aduanero
}

\author{
Guarantee of due process hearing, human right \\ violated to the importer in the customs procedure
}

\author{
Gabriela Aguado Romero ${ }^{1} \bowtie$ \\ ${ }^{1}$ Doctora en Derecho. Profesor investigador de tiempo completo, Universidad Autónoma \\ de Querétaro, México..
}

Correo electrónico: aguadogabriela@hotmail.com

Recibido: 11 de agosto del 2018 Aprobado: 10 de octubre del $2018 \quad$ Disponible en línea: 5 de enero del 2019

Cómo citar este artículo: Gabriela Aguado Romero. Garantía de audiencia-debido proceso. Transgresión del derecho humano al importador en el procedimiento aduanero. DIxı 28. Julio 2018. doi: https://doi.org/10.16925/2357-5891.2018.02.07

\begin{abstract}
Resumen
Objetivo: el propósito del presente estudio es realizar un análisis del derecho humano a la garantía de audiencia-debido proceso, reconocido tanto en la Constitución Política de los Estados Unidos Mexicanos como en el derecho internacional de los derechos humanos. Encontramos que este derecho humano se ve transgredido en el ámbito aduanal, dentro de la legislación secundaria. Esta violación se presenta cuando se soslaya el principio de legalidad y se otorga con esto un margen de discrecionalidad a favor de la autoridad aduanal en contra de la figura del importador.

Metodología: para el desarrollo del presente estudio se empleará una metodología exegética y el uso de la técnica documental bibliográfica.

Resultados: dado lo anterior, se observa una falta de armonización para la protección de los derechos humanos, pues a pesar de que la reforma constitucional del 2011, en materia de derechos humanos, trae aparejado un cambio en la forma de interpretar la Constitución y los tratados internacionales de los que el Estado mexicano sea parte, es evidente que la legislación en materia aduanera en México aún contiene disposiciones que transgreden el derecho humano a la garantía de audiencia-debido proceso, entre otros.

Hallazgos: el Estado incumple con la obligación de respetar, proteger, promover y garantizar el ejercicio y goce de los derechos humanos y las libertades fundamentales de las personas que se encuentran dentro de su jurisdicción.
\end{abstract}

Palabras clave: aduanero, constitución, derechos humanos, derecho internacional, garantía de audiencia-debido proceso. 


\title{
Guarantee of due process hearing, human right violated to the importer in the customs procedure
}

\begin{abstract}
Purpose: The purpose of this study is to make an analysis about the human right called guarantee of due process hearing, recognized in the Political Constitution of the United Mexican States and in the International Law of Human Rights. We can see that nowadays this human right is violated in the customs department, within the second legislation. This violation happens when the principle of legality is ignored, granting a margin of discretion in favor of the customs authority against the importer.

Methods:

Results: Analyzing this situation, we can observe there is a lack of harmonization to protect human rights, despite the fact that the constitutional reform of 2011 in the field of human right, brings a different way to interpret ate the Constitution and the international treaties in which Mexico is involved, it is obvious that the legislation on customs matters in Mexico, still has sections that transgress, among others, the guarantee of due process hearing.

Conclusions: State fails to comply with the obligation to respect, protect, promote and guarantee the enforcement and enjoyment of the human rights and fundamental freedoms of citizens who are within its jurisdiction.
\end{abstract}

Keywords: customs, constitution, human rights, international law, guarantee of due process hearing.

\section{Garantia de audiência-devido processo, direito humano transgredido ao importador no procedimento alfandegário}

\section{Resumo}

Objetivo: o propósito deste estudo é realizar uma análise do direito humano à garantia de audiência-devido processo, reconhecido tanto na Constituição Política dos Estados Unidos Mexicanos quanto no Direito Internacional dos Direitos Humanos. Verificamos que esse direito humano é violado no âmbito alfandegário, dentro da legislação secundária. Essa violação é apresentada quando se evita 0 princípio de legalidade, outorgando, com isso, uma margem de discricionariedade a favor da autoridade alfandegária contra a figura do importador.

Metodologia: para o desenvolvimento deste estudo, emprega-se uma metodologia exegética e 0 uso da técnica documental bibliográfica.

Resultados: com isso, observa-se uma falta de harmonia para proteger os direitos humanos, já que, apesar da reforma constitucional de 2011 em matéria de direitos humanos, implica uma mudança na forma de interpretar a Constituição e os tratados internacionais dos quais o Estado mexicano faz parte; é evidente que a legislação quanto ao tema no México ainda contém disposições que transgredem entre outros 0 direito humano à garantia de audiência-devido processo.

Achados: 0 Estado não cumpre com a obrigação de respeitar, proteger, promover e garantir o exercício e 0 gozo dos direitos humanos e das liberdades fundamentais das pessoas que se encontram em sua jurisdição.

Palavras-chave: garantia de audiência-devido processo, constituição, direito internacional, direitos humanos, alfandegário. 


\section{I.INTRODUCCIÓN}

Es necesario hacer un reconocimiento de los derechos fundamentales dentro de los procedimientos legales y no olvidar que estos principios básicos no deben vulnerarse; por el contrario, se deben vigilar y promover.

Los derechos humanos, entendidos como prerrogativas esenciales del trato entre iguales, han evolucionado a lo largo del tiempo de tal forma que, hoy en día, se reconoce como un derecho humano fundamental el debido proceso, entre otros.

Anteriormente, esta garantía se dirigía, sobre todo, al proceso judicial; luego, se reconoció en los procedimientos administrativos ${ }^{1}$, en los que su cumplimiento en el desarrollo de procedimientos legales es obligatorio. Dichas prerrogativas fundamentales son de una gran observancia e importancia, al grado que diferentes mecanismos internacionales, nacionales e incluso doctrinales las reconocen.

A último momento, se da la incorporación del concepto derechos humanos en la Constitución Política de los Estados Unidos Mexicanos y, a partir de esto, es obligatorio respetar y seguir pautas mínimas en el desarrollo de los procedimientos que se llevan a cabo en México. Además, debemos tener presente que su observancia es obligatoria, lo cual se advierte en el contenido del artículo primero constitucional, pues queda plasmado que México ha adoptado una protección amplia de los derechos humanos, entre estos el de debido proceso.

Mediante el reconocimiento claro del principio pro persona se brinda mayor protección, ya que las autoridades, al aplicar normas de derechos humanos, deben preferir la norma o la interpretación más favorable a la persona; de este modo, se sostiene que debe tenerse en cuenta esencialmente lo justo, es decir, que prevalezca la situación imparcial y razonable, antes que las normas organizadas en sistema. Con esto se evidencia que la Constitución mexicana de 1917 dejó de ser solo un ordenamiento positivo con normas impositivas, para evolucionar a un texto jurídico de contenido moral que opera también a partir de valores.

1 En el proceso judicial se reconocía dicha garantía desde 1215, mientras que, en el procedimiento administrativo, no es sino hasta 1615, en el caso Bagg, cuando un habitante de Plymouth fue sancionado por el alcalde sin ser escuchado y los tribunales sostuvieron que la sanción era nula porque al afectado no se le concedió una audiencia previa. Véase Arturo Hoyos. Debido PRoceso y DEMOCRACIA. Pág. 148. Porrúa. (2006).
A raíz de la reforma de derechos humanos del 10 de junio de 2011, se enfatiza que la Constitución se encuentra a la par de los tratados internacionales que, de igual manera, obligan al cumplimiento y la observancia del debido proceso como derecho humano, pues nos encontramos dentro de un proceso jurídico globalizador:

Un sistema universal sobre los sistemas regionales, esto implica una evolución gradual de la figura del Estado en aras de un avance progresivo hacia la construcción de una comunidad mundial, en donde la observancia de los derechos humanos se encuentra protegida por un control internacional que atraviesa las fronteras de los Estados, buscando el cumplimiento de fines y valores universales. La tradición humanística común debe ser el lugar donde confluyan las tendencias opuestas de los Estados respecto a los derechos humanos ${ }^{2}$.

En lo anterior queda plasmado cómo los mencionados ordenamientos jurídicos indican que siempre se velará por lo más favorable para la persona; sin embargo, el derecho humano al debido proceso, lejos de ser respetado, es violentado de manera sistemática y concurrida en materia aduanera en México.

Por referir un caso específico de esta inobservancia y, por tanto, una vulneración de los derechos humanos, señalaremos que, en relación con el procedimiento aduanero, existen diferentes ordenamientos jurídicos que facultan el actuar de las autoridades; entre estos se encuentran la Ley Aduanera Mexicana, el Código Fiscal de la Federación, el Manual de Operación Aduanera, el Reglamento Interior del Servicio de Administración Tributaria y las Reglas Generales de Comercio Exterior. Al realizar un análisis de su contenido, se puede observar una falta de delimitación clara y específica de las facultades de la autoridad. Asimismo, ocurre en otros supuestos previstos en estos ordenamientos que las facultades concedidas a la autoridad para llevar a cabo un procedimiento aduanero se encuentran especificadas de manera clara y precisa, pero van más allá de lo que prevé la Constitución y los tratados internacionales

2 Véase Gabriela Aguado Romero, Noemí Bello Gallardo y Alina del Carmen Nettel. Un espacio judicial para una teoría naturalizada de los derechos humanos. Coord. Gabriela Aguado Romero, Noemí Bello Gallardo y Alina del Carmen Nettel. Derecho ADMINISTRATIVO. UN ÁMBITO DE RESPETO, PROMOCIÓN, PROTECCIÓN Y GARANTÍA DE Los DEREChos humanos. Tirant lo Blanch. (2016). Pág. 47. 
para garantizar un debido proceso: "Es de explorado derecho, que todas las actuaciones de las autoridades deben estar regidas por las normativas jurídicas que le son aplicables a fin de calificarse de legales"3.

Con esto podemos afirmar que no siempre el ordenamiento positivo en una materia específica, como, por ejemplo, lo es el ordenamiento aduanero, contempla en sus contenidos principios que brinden mayor protección al gobernado. Con esto, dejan de armonizar con lo que establece la Constitución Política de los Estados Unidos Mexicanos y los instrumentos internacionales en materia de derechos humanos, entre estos lo previsto en los instrumentos internacionales de derechos económicos, sociales y culturales.

Ante un positivismo tan extendido - como es el caso del que prevalece en el ordenamiento jurídico mexicano-, y ante un exceso legislativo que, en vez de evitar los conflictos y las situaciones problemáticas en nuestro país complica más la tarea de darles solución ${ }^{4}$, se contrapone el hecho de que pocas veces los derechos humanos han sido de tal modo proclamados como lo vemos en las sociedades actuales; cada vez se exige más su cumplimiento. Tales derechos son naturales, tienen origen y fundamento en el hombre mismo; son esenciales, derivados de la dignidad inherente de la persona y se reconocen, no se crean por los ordenamientos positivos.

A fin de referir con más precisión la problemática a tratar, podemos decir que, cuando se concede una facultad discrecional a las autoridades aduaneras, en ciertos casos se deja de lado el principio de legalidad, así como el principio de garantía de audiencia-debido proceso, lo que vulnera de manera grave la esfera jurídica del gobernado.

Por tanto, para el desarrollo del presente estudio se emplea una metodología exegética y se utiliza la técnica documental (bibliográfica en específico). Al aplicar estas metodología y técnicas perseguimos describir y explicar los hechos. Se ejemplifica el problema mediante un análisis de los artículos 152 y 158 de la Ley Aduanera, en los que se observan evidentes violaciones a los derechos del importador, pues lo dejan en estado de indefensión, al no permitirle ejercer su

Véase Nohemí Bello Gallardo y Luis Eusebio Alberto Avendaño González. La garantía de audiencia en algunos procedimientos aduaneros. Letras jurídicas 31. Enero-junio. 2016. Pág. 32.

4 Gabriela Aguado Romero, Noemí Bello Gallardo y Alina del Carmen Nettel, supra, nota 2, pp. 61-63. derecho humano de garantía de audiencia-debido proceso.

Se hace necesario un análisis sobre estos actos jurídicos de afectación directa en la esfera jurídica de la persona, revisar la fundamentación de la autoridad para llevar a cabo dichos actos y proponer una observancia del debido proceso con respeto por la garantía de audiencia en los procedimientos aduaneros, tal como lo dispone la Constitución y los instrumentos internacionales de derechos humanos. Sin embargo, también en el presente estudio se puntualiza la propuesta de solución en armonizar los ordenamientos aduaneros mexicanos con lo dispuesto en los instrumentos internacionales de derechos económicos, sociales y culturales que advierten crecimiento económico y protegen derechos humanos. Aplicar los instrumentos internacionales en materia de derechos económicos, sociales y culturales es uno de los deberes que el Estado mexicano debe cumplir para su protección y promoción.

En épocas de incertidumbre económica, la adecuada garantía y protección del derecho al debido proceso resulta crítica y el Estado tiene la obligación de velar por la vigencia de los derechos humanos, en procura de su eficacia.

\section{II.GARANTÍA DE AUDIENCIA-DEBIDO}

\section{PROCESO COMO DERECHO HUMANO}

Desde una visión histórica, el debido proceso se contempló como una institución en el derecho inglés desde antes de su implementación en América, a su llegada al Nuevo Continente, donde lo instauraron como "la institución del debido proceso". Al respecto señala Linares:

La institución del debido proceso legal en el momento de su trasplante a las colonias de Norteamérica, tenía las dos siguientes características: a) Era una mera garantía procesal de la libertad personal contra las detenciones arbitrarias del Estado y accidentalmente, contra las penas pecuniarias y confiscaciones, es decir, contra penas sin juicio legal por los países. No obstante, debe reconocerse que ya en las Institutas de Edward Coke había anticipos claros de la posibilidad de que pudiera constituir una garantía contra la aplicación injusta de las normas del Common Law o aún de los estatutos. b) El debido proceso ofrecía 
garantías contra la arbitrariedad del monarca y de los jueces, pero no del parlamento ${ }^{5}$.

Es así como esta tendencia a la observancia de lineamientos mínimos trasciende a los ordenamientos jurídicos de nueva creación en el continente. De igual forma, en 1866, Estados Unidos convirtió el debido proceso en parte de la enmienda $\mathrm{XIV}^{6}$.

En un sistema jurídico de la familia del common law, como lo es el sistema jurídico de los Estados Unidos, tenemos que la Corte Federal ha consignado el concepto de debido proceso al menos en dos garantías mínimas:

a) Due process procesal, que significa que ningún órgano jurisdiccional puede privar a las personas de la vida, libertad o propiedad, a excepción que tenga la oportunidad de alegar y ser oída, y b) Due process sustantivo, que quiere decir que el gobierno no puede limitar o privar arbitrariamente a los individuos de ciertos derechos fundamentales contenidos en la Constitución. De esta forma se crea un poder de control sobre la discrecionalidad administrativa? ${ }^{7}$.

Una constante asimilación del concepto implica su paso de una etapa histórica a otra. Para Cipriano Gómez Lara, "el resultado del proceso evolutivo para el reconocimiento de la garantía del debido proceso en el siglo xx se resume en: a) la constitucionalización de las garantías procesales, y b) la protección de estas mismas garantías o derechos en instrumentos internacionales".

Todo reconocimiento de derechos es el resultado de un análisis y de la proyección de las necesidades sociales dentro de un sistema jurídico: "El proceso es un instrumento para solucionar ciertos tipos de conflictiva social... el cual permite el mantenimiento de ese equilibrio de las relaciones jurídicas

5 Véase Juan Francisco Linares. LA RAzONABILIDAD DE LAS LEYEs. $2^{a}$ edición. Astrea. (1989). Pág. 16. Al referirse en el inciso a) a las penas sin juicio legal por los pares, se entiende en relación con ser juzgado por un igual; en razón a la jerarquía clasista, se refiere a ser juzgado por alguien del mismo estatus económico y social.

$6 \quad I d$.

7 Véase Osvaldo Alfredo Gozaíni. El debido proceso consTITUCIONAL. REgLAS PARA EL CONTROL DE LOS PODERES DESDE LA MAgistratura Constitucional. Instituto de Investigaciones Jurídicas. (2011).

8 Véase Cipriano Gómez Lara. El debido proceso como DERECHO HUMANO. Instituto de Investigaciones Jurídicas. (2006). Pág. 342. contrapuestas". Visto el proceso como un instrumento que fija las reglas básicas a seguir, y el cual, por orden constitucional, no debe contraponerse ni violentar de forma alguna los derechos humanos, de igual forma diferentes ordenamientos internacionales hacen un reconocimiento expreso del respeto a los derechos que protegen a las personas involucradas en un proceso legal.

Por su parte, el derecho procesal se define como el "conjunto de normas y principios jurídicos que regulan tanto el proceso jurisdiccional como la integración y competencia de los órganos del Estado que intervienen en el mismo"10.

La Corte Interamericana de Derechos Humanos, en el caso Genie Lacayo, párrafo 74, define el debido proceso en los siguientes términos:

El derecho de toda persona a ser oída con las debidas garantías y dentro de un plazo razonable por un juez o tribunal competente, independiente e imparcial, establecido con anterioridad por la ley, en la sustanciación de cualquier acusación penal formulada en su contra o para la determinación de sus derechos de carácter civil, laboral, fiscal u otro cualquiera ${ }^{11}$.

Dentro de la fuente jurisprudencial a nivel nacional, si se busca en el mencionado Sistema de Tesis y Jurisprudencias de la Suprema Corte de Justicia de la Nación, denominado "IUs", las palabras "debido proceso", el resultado arrojado es de 490 elementos solo de la novena y décima época. En razón a lo anterior, podemos observar que ha sido un tema recurrente y de peso en el sistema jurisdiccional mexicano.

La Suprema Corte de Justicia de la Nación, en la tesis de jurisprudencia 11/2014, establece:

Las garantías del debido proceso que aplican a cualquier procedimiento de naturaleza jurisdiccional son las que esta SCJN ha identificado como formalidades esenciales del procedimiento, cuyo conjunto integra la "garantía de audiencia", las cuales permiten que

9 Véase Cipriano Gómez Lara. Teoría general del Proceso. 8a edición. Harla. (1990). Pág. 2.

10 Véase José Ovalle Favela. Teoría General Del Proceso. 6a edición. Oxford. (2005). Pág.39.

11 Corte Interamericana de Derechos Humanos. Caso GeniE LaCAyo, sentencia. (Enero 29 de 1997). Serie C N. ${ }^{\circ} 21$. Párrafo 74. Disponible en: http://www.corteidh.or.cr/docs/casos/articulos/ seriec_30_esp.pdf. 
los gobernados ejerzan sus defensas antes de que las autoridades modifiquen su esfera jurídica definitivamente $^{12}$.

Al ser esta jurisprudencia obligatoria desde el 3 de marzo del 2014, define también dichas formalidades esenciales del procedimiento, esto es, para un desarrollo de la actuación de la autoridad conforme al debido proceso.

Deja claro que la garantía de audiencia-debido proceso no es un concepto de reciente creación, sino que ha sido reconocida su tutela como una necesidad del individuo orientada a la protección de la persona ante las actuaciones de la autoridad.

En nuestro país, el organismo denominado "Comisión Nacional de los Derechos Humanos" define el Debido Proceso como "el derecho que tiene toda persona para ejercer su defensa y ser oída, con las debidas oportunidades y dentro de un plazo razonable, por la autoridad competente previo al reconocimiento o restricción de sus derechos y obligaciones"13. Además, establece como requisitos mínimos que contenga las siguientes garantías: el aviso de inicio del procedimiento; la oportunidad de ofrecer pruebas y alegar; una resolución que resuelva las cuestiones debatidas; y la posibilidad de reclamar la resolución mediante un recurso eficaz.

De tal forma, entendemos que el debido proceso es una prerrogativa básica que debe ser de observancia general, respetada, promovida y vigilada su aplicación, como derecho humano contemplado en la Constitución mexicana: "A ninguna ley se dará efecto retroactivo en perjuicio de persona alguna. Nadie podrá ser privado de la libertad o de sus propiedades, posesiones o derechos, sino mediante juicio seguido ante los tribunales previamente establecidos, en el que se cumplan las formalidades esenciales del procedimiento y conforme a las Leyes expedidas con anterioridad al hecho"14.

Asimismo, que protege al gobernado frente al acto de autoridad: "Nadie puede ser molestado en su persona, familia, domicilio, papeles o posesiones, sino en virtud de mandamiento escrito de la

12 Véase Tesis 1 a/J. 11/2014. Semanario judicial de La FedeRACión y SU GaCeta. Décima Época, t. I. Febrero de 2014. Pág. 396.

13 Véase Comisión Nacional de los Derechos Humanos. Debido Proceso. (2018). Disponible en http://www.cndh.org.mx/ Derecho_Audiencia_Proceso_Legal.

14 Véase Constitución Política de los Estados Unidos Mexicanos [Const]. Art.14. Febrero 5 de 1917 (México). autoridad competente, que funde y motive la causa legal del procedimiento"15.

En los citados ordenamientos se reconocen principios básicos para el desarrollo de un proceso sin violentar los derechos humanos de la persona sujeta a este y, sobre todo, el hecho de que, a nadie ninguna autoridad le puede modificar su esfera jurídica sin que previamente el gobernado ejerza su defensa ante esta.

Se requieren pautas básicas del desarrollo de un procedimiento apegado a los derechos humanos para brindar protección y certeza jurídica al gobernado con respecto al actuar de la autoridad, así como la vigilancia de la observancia de estos preceptos mínimos de protección de los derechos de los individuos.

La reforma constitucional del 10 de junio de 2011 en materia de derechos humanos, por la cual se cambia el título primero, capítulo primero, que anteriormente se denominaba "De las garantías individuales", por la denominación actual "De los derechos humanos y sus garantías", trae como consecuencia diversos cambios en la forma de interpretar la Constitución y, en consecuencia, en la forma de interpretar cualquier ordenamiento, con lo que crea una línea horizontal con toda la normatividad en sus diferentes materias. A raíz de esta reforma, en el artículo primero constitucional se señala la obligación del Estado mexicano (en todos sus niveles de gobierno, sin excepción) de promover, respetar, proteger y garantizar los derechos humanos. De esta forma, queda claro que todo derecho humano reconocido por la Constitución y los tratados internacionales genera obligaciones para las autoridades mexicanas, con independencia del nivel de gobierno que ocupen o de la modalidad administrativa bajo la que estén organizadas.

\section{INSTRUMENTOS INTERNACIONALES} QUE PROTEGEN EL DERECHO HUMANO A LA GARANTÍA DE AUDIENCIA-DEBIDO PROCESO

A nivel internacional, encontramos una serie de instrumentos tanto no vinculantes como vinculantes que refieren una obligación directa, a cargo de las autoridades que se encuentran dentro de un Estado parte, de respetar, proteger, promover y garantizar los derechos humanos y las libertades fundamentales de las personas sin distinción alguna.

15 Id. Art.16. 
Con relación al derecho humano de garantía de audiencia-debido proceso, encontramos instrumentos tanto universales como regionales que protegen este derecho.

\section{A. Los instrumentos internacionales de carácter universal}

\section{La Declaración Universal de Derechos Humanos}

Es uno de los ordenamientos más importantes a nivel mundial, en el cual se lee: "Toda persona tiene derecho, en condiciones de plena igualdad, a ser oída públicamente y con justicia por un tribunal independiente e imparcial, para la determinación de sus derechos y obligaciones o para el examen de cualquier acusación contra ella en materia penal"16. En este sentido, obliga el mencionado instrumento internacional a otorgar una protección mayor a la persona, asegurándole todas las garantías necesarias para su defensa: "Toda persona acusada de delito tiene derecho a que se presuma su inocencia mientras no se pruebe su culpabilidad, conforme a la ley y en juicio público en el que se le hayan asegurado todas las garantías necesarias para su defensa" ${ }^{17}$. También dispone que toda persona tiene derecho a un recurso efectivo que se lleve a cabo ante los tribunales competentes, lo cual la proteja contra actos que violen sus derechos $^{18}$.

\section{El Pacto Internacional de Derechos Civiles y Políticos}

Suscrito el 16 de diciembre de 1966, entró en vigor el 23 de marzo de 1976. Hasta la fecha ha sido ratificado por 172 países, entre los cuales México la ratificó el 20 de mayo de 1981. Establece que es un derecho humano de toda persona (que el Estado debe garantizar) la interposición de un recurso efectivo por la violación de esos derechos o libertades ante autoridad competente, quien decidirá sobre sus derechos ${ }^{19}$.

\section{B. Los instrumentos internacionales de carácter regional}

\section{La Declaración Americana de los Derechos y Deberes del Hombre}

Señala que toda persona tiene el derecho de acudir ante los tribunales para hacer valer sus derechos mediante un procedimiento sencillo y breve contra actos de autoridad que violen sus derechos fundamentales ${ }^{20}$.

2. La Convención Americana sobre Derechos Humanos (Pacto de San José)

Suscrita el 22 de noviembre de 1969, entró en vigor el 18 de julio de 1978. Hasta la fecha ha sido ratificada por 25 países, entre los cuales México la ratificó el 2 de marzo de 1981. Dicha convención dispone que toda persona tiene derecho a ser oída dentro de un plazo razonable y ante un tribunal competente establecido con anterioridad por la ley ${ }^{21}$. Lo anterior en conformidad con lo previsto en el artículo 8 de la Convención Americana sobre Derechos Humanos que, como señala Federico Thea,

en rigor de verdad, más que un pilar del sistema de protección de los derechos humanos, parece más acertado afirmar que el artículo 8 de la Convención Americana contiene un conjunto de pilares, que sostienen la tutela de los demás derechos de las personas. Ellos son, entre otros y sin perjuicio de las particularidades de su ámbito de aplicación y de la extensión que le ha dado a cada uno la jurisprudencia nacional e internacional, las garantías de acceso a la jurisdicción, intervención del juez natural, independiente e imparcial, presunción de inocencia, igualdad de las partes y equidad de los procedimientos, inviolabilidad de la defensa en juicio y decisión justa, conforme a derecho, dictada dentro de un plazo razonable ${ }^{22}$.

20 Cf. Declaración Americana de los Derechos y Deberes de Hombre [DAdydh]. Art. XviII. Mayo 2 de 1948 (Colombia).

21 Cf. Convención Americana de los Derechos Humanos [CADH] Art. 8. Julio 18 de 1978 (Costa Rica).

22 Véase Federico G. Thea. Artículo 8. Garantías judiciales. Enrique Alonso Regueira. La CONVENCIÓN AMERICANA DE DERECHOS HUMANOS Y SU PROYECCIÓN EN EL DERECHO ARGENTINO. Fedye. (2013). Pág. 128.

\footnotetext{
16 Véase Declaración Universal de Derechos Humanos [DUDH] Arts. 10. Diciembre 10 de 1948 (Francia).

17 Id. Art. 11

18 Id. Art. 8.

19 Cf. Pacto Internacional de Derechos Civiles y Políticos [PIDCYP] Art. 2.3 Marzo 23 de 1976 (EUA).
} 
En cuanto al procedimiento, dispone que deberá ser sencillo y rápido ${ }^{23}$.

A continuación, se presenta una tabla en la que se refieren los instrumentos internacionales que protegen el derecho humano a la garantía de audiencia-debido proceso. Dichos instrumentos se organizan en razón de su tipología, es decir, de su obligatoriedad, del área geográfica y de los sujetos a quienes va dirigido.

Tabla 1. Instrumentos internacionales que prevén la garantía de audiencia

\begin{tabular}{|l|l|l|l|}
\hline \multicolumn{2}{|c|}{ Carácter } & \multicolumn{1}{c|}{ Vinculantes } & No vinculantes \\
\hline \multirow{4}{*}{ Generales } & \multirow{2}{*}{ Universales } & $\begin{array}{l}\text { Pacto Inter- } \\
\text { nacional De } \\
\text { Derechos Civiles } \\
\text { y Políticos }\end{array}$ & $\begin{array}{l}\text { Declaración } \\
\text { Universal de } \\
\text { los Derechos } \\
\text { Humanos }\end{array}$ \\
\cline { 3 - 4 } & \multirow{2}{*}{ Regionales } & $\begin{array}{l}\text { Convención } \\
\text { Americana } \\
\text { sobre Derechos } \\
\text { Humanos (Pacto } \\
\text { de San José) }\end{array}$ & $\begin{array}{l}\text { Declaración } \\
\text { Americana de } \\
\text { los Derechos } \\
\text { y Deberes del } \\
\text { Hombre }\end{array}$ \\
\hline
\end{tabular}

Elaboración propia.

En la tabla 1 se muestran aquellos instrumentos internacionales que contemplan el derecho humano a la garantía de audiencia-debido proceso. Estos instrumentos son de carácter general, pues están dirigidos a proteger los derechos humanos de todas las personas. Entre ellos encontramos dos de carácter no vinculante (las declaraciones), esto es, no son obligatorias para los Estados parte. Por tal motivo, se suscribieron tanto el pacto como la convención, es decir, con el propósito de dar fuerza vinculante a los derechos consagrados en las declaraciones.

Como se pudo observar en este apartado, señalamos en razón de su importancia los instrumentos internacionales en materia de derechos humanos que contemplan el derecho humano a la garantía de audiencia-debido proceso.

Sin embargo, al revisar la garantía de audiencia-debido proceso como derecho humano, así como los instrumentos internacionales que prevén su protección, surge una duda: ¿En verdad se respetan estas prerrogativas básicas de protección del gobernado contra actos de autoridad, o son simplemente

23 Cf. Convención Americana de los Derechos Humanos, supra, nota 22. Art. 25 un reconocimiento positivizado de un derecho que fácticamente se vulnera de manera reiterada?

\section{VI.AlgunOS SUPUESTOS DE VULNERACIÓN DE LA GARANTÍA DE AUDIENCIA-DEBIDO PROCESO DENTRO DEL PROCEDIMIENTO ADUANERO}

Todo reconocimiento de un derecho surge de una necesidad de la población y de la evolución de las instituciones.

El derecho humano de garantía de audiencia-debido proceso es el resultado de un camino recorrido de lucha por parte de las personas a fin de evitar los atropellos dentro de los procesos y lograr el reconocimiento de un derecho que les garantice su defensa frente a la autoridad, antes de ver afectada gravemente su esfera jurídica como gobernados.

En materia aduanera, el resultado de determinados procedimientos por parte de la autoridad suelen tener consecuencias sumamente gravosas para el ciudadano implicado.

A continuación, se señalan algunos procedimientos que se encuentran previstos en el ordenamiento y la regulación aduanera aplicable en México; en específico, se realizará el análisis de los artículos 152 y 158 de la Ley Aduanera, en el cual se observan evidentes violaciones a los derechos del importador, en cuanto ciudadano implicado en un procedimiento, lo que lo deja en estado de indefensión al no permitirle ejercer su derecho humano de garantía de audiencia-debido proceso.

Dentro del procedimiento aduanero de verificación de origen estipulado, la Ley Aduanera vigente en México establece lo siguiente:

En los casos en que con motivo del reconocimiento aduanero, de la verificación de mercancías en transporte, de la revisión de los documentos presentados durante el despacho o del ejercicio de las facultades de comprobación, en que proceda la determinación de contribuciones omitidas, aprovechamientos y, en su caso, la imposición de sanciones no sea aplicable el artículo 151 de esta Ley, las autoridades aduaneras procederán a su determinación, sin necesidad de sustanciar el procedimiento establecido en el artículo 150 de esta Ley. [...] Cuando no se requiera la toma de muestras para su identificación, la autoridad 
aduanera dará a conocer mediante escrito o acta circunstanciada, los hechos u omisiones que impliquen la omisión de contribuciones, cuotas compensatorias $\mathrm{y}$, en su caso, la imposición de sanciones ${ }^{24}$.

Lo primero que es necesario señalar es que el artículo descarta para este supuesto lo previsto en el artículo 151 de la Ley Aduanera, el cual dispone los casos en los que las autoridades aduaneras procederán al embargo precautorio de las mercancías y de los medios en que se transporten.

Por otra parte, también descarta para este supuesto la sustanciación del procedimiento establecido en el artículo 150 de la Ley Aduanera, por el cual se dispone la obligación de las autoridades aduaneras de levantar un acta al inicio del procedimiento administrativo en materia aduanera.

La disposición que prevé el procedimiento aduanero de verificación de origen estipulado en la Ley Aduanera faculta a la autoridad aduanera para que proceda a la determinación de contribuciones omitidas, aprovechamientos y la imposición de sanciones, en un mismo momento, sin oportunidad de que el gobernado que intenta realizar una importación exprese lo que a su interés convenga y presente pruebas antes de que se le determine y sancione.

Contrario a otorgar la garantía de audiencia que dispone un debido proceso señala que en el ejercicio de sus facultades de comprobación, las autoridades aduaneras procederán a la retención de las mercancías o de los medios de transporte, en los siguientes casos:

I. Cuando con motivo del reconocimiento aduanero, o verificación de mercancía en transporte, no se presente el documento en el que conste el depósito efectuado en la cuenta aduanera de garantía en el caso de que el valor declarado sea inferior al precio estimado; y II. Cuando con motivo del reconocimiento aduanero no se acredite el cumplimiento de normas oficiales mexicanas de información comercial ${ }^{25}$.

Del análisis de las disposiciones anteriores se puede observar que la Ley Aduanera no prevé en los párrafos citados la intervención del sujeto afectado (en este caso, el importador). Esto no permite que se desarrolle un procedimiento conforme al debido proceso, lo cual niega y viola los derechos humanos

24 Ley Aduanera [LA] Arts. 152. Diciembre 15 de 1995 (México). 25 Id. Arts. 158. del importador, de manera que lo deja en un estado de indefensión frente a los actos de autoridad aduanera. Así, también, es nula su participación y la oportunidad de que ofrezca prueba en contrario, a fin de intentar refutar y defenderse frente al acto que modifica su esfera de derechos.

Para que pudiese existir la garantía de audiencia-debido proceso es necesario que se vean cubiertos los parámetros mínimos establecidos constitucionalmente por la doctrina, los ordenamientos internacionales, las prerrogativas básicas de desarrollo del proceso legal y la necesaria observancia de dichos parámetros dentro del proceso, en pos de un respeto total de los derechos humanos; fundamentalmente, de la garantía de audiencia-debido proceso de los sujetos afectados por los actos de autoridad aduanera.

De primera instancia, nos parecen simples omisiones de la autoridad que no tienen mayor relevancia; sin embargo, al analizarlos con detenimiento caemos en cuenta de que se trata de pautas dadas por nuestra Constitución, de manera que la doctrina y los mecanismos internacionales que se violan sistemáticamente.

\section{V.COMPATIBILIDAD DEL ORDENAMIENTO ADUANERO CON LOS INSTRUMENTOS INTERNACIONALES DE DERECHOS ECONÓMICOS, SOCIALES Y CULTURALES}

A continuación, se examina la compatibilidad que tiene el ordenamiento aduanero con los instrumentos internacionales en materia de derechos económicos, sociales y culturales.

Los derechos humanos se dividen en diferentes categorías: los derechos civiles, políticos, económicos, sociales y culturales. Si bien es posible encontrar un catálogo de los derechos humanos en la Declaración Universal de los Derechos Humanos, también se incluyen otros instrumentos legales. Con relación, en específico, a los derechos económicos, sociales y culturales, se encuentran protegidos por diversos tratados internacionales y regionales, así como por las constituciones nacionales. Existe, por ejemplo, el Pacto Internacional de los Derechos Económicos, Sociales y Culturales (Pidesc), el tratado más exhaustivo que estipula la protección a dichos derechos a nivel internacional, aprobado en 1966; contiene un catálogo de estos derechos y establece que deben ser 
reconocidos por los Estados. Al ser México un Estado parte de este pacto, ha de observar y velar por su cumplimiento, al igual que debe promocionar estos derechos y tener en cuenta las circunstancias nacionales. Se supone que, a través de la ratificación de los pactos y tratados internacionales, los gobiernos se comprometen a tomar medidas y tener leyes internas que sean compatibles con las obligaciones y los deberes que dimanan de ellos.

Conforme a lo expuesto, se puede afirmar que no existe compatibilidad entre los ordenamientos aduaneros mexicanos y los instrumentos internacionales de derechos económicos, sociales y culturales. Por tanto, es necesario armonizarlos. La importancia de su compatibilidad radica en que, actualmente, el crecimiento económico representa una solución a diversos problemas en México. Las pequeñas y medianas empresas de comercio exterior de nuestro país representan un área de oportunidad para el crecimiento económico, de manera que resulta necesario resaltar que la compatibilidad entre el ordenamiento jurídico nacional y los instrumentos internacionales de derechos económicos, sociales y culturales da lugar, además de un crecimiento económico, a la protección de los derechos humanos en nuestro país.

El crecimiento económico debería ser uno de los objetivos primordiales, y los ordenamientos tanto fiscales como aduaneros deberían favorecer al sector privado para el fortalecimiento del comercio exterior (importación/exportación). Sin embargo, esto no se ha visto reflejado y, por el contrario, vemos que hoy en día esta incompatibilidad solo ha reportado un descenso económico.

Los instrumentos internacionales de derechos económicos, sociales y culturales advierten crecimiento económico y protección de los derechos humanos, sin embargo, el ordenamiento aduanero mexicano no refleja compatibilidad con ellos. Frente a esto es importante cuestionarnos si esto implica una herramienta o una barrera para los importadores mexicanos que apenas están consolidándose. Si bien el comportamiento de las empresas ha cambiado de forma paulatina (un número mayor de organizaciones realizan actividades de carácter internacional), esto no ha repercutido en que las empresas mexicanas tengan una sólida presencia en la escena internacional ${ }^{26}$.

$26 C f$ Ian Fillis. Small firm Internationalisation: an investigative survey and future research directions. JouRNAL OF MANAGEMENT DECISION 39(9). 2001. Págs. 767-783.
La propuesta de Adam Smith para el correcto funcionamiento de una economía de mercado es que el Estado debe regular e intervenir a fin de garantizar el acceso a todos los agentes económicos a los mecanismos de mercado, lo que posibilita una economía de mercado abierta a todos los hombres ${ }^{27}$. Lo anterior, si se tiene en cuenta que la desigualdad en el acceso al financiamiento y en las condiciones de acceso para las empresas de menor tamaño constituye un eje de la reproducción de la heterogeneidad estructural y las desigualdades sociales ${ }^{28}$. En razón a lo anterior, se duda de la compatibilidad entre los ordenamientos aduaneros mexicanos y los instrumentos internacionales de derechos económicos, sociales y culturales.

Fomentar el crecimiento económico de México, al mitigar las diferentes formas de exclusión económica y así lograr la inserción a las cadenas de valor de los sectores estratégicos de mayor dinamismo, implica realizar las adecuaciones necesarias a los ordenamientos aduaneros mexicanos conforme a la protección de los derechos humanos que prevén los instrumentos internacionales de derechos económicos, sociales y culturales (tratados, convenciones, pactos y protocolos), de los que México forma parte. Es esta una situación de relevante importancia para constituir un núcleo más dinámico de inserción internacional, un papel que debe tomar el Estado mexicano frente a la globalización.

Aplicar los instrumentos internacionales en materia de derechos económicos, sociales y culturales que protegen derechos humanos es uno de los deberes que el gobierno debe cumplir para su protección y promoción.

\section{VI.CONCLUSIONES}

Luego del análisis realizado alrededor de la problemática que representa colocar al gobernado en un estado de indefensión e incertidumbre jurídica con respecto del actuar de la autoridad, esto es, violar su derecho a la garantía de audiencia-debido proceso, sin dejar de lado el hecho de que la garantía de audiencia-debido proceso es un derecho humano reconocido por un gran número de instrumentos

27 Cf Adam Smith. INVESTIGACIÓN DE LA NATURALEZA Y CAUSA DE LA RIQUEZA DE LAS NACIONES. Oficina de la Viuda e Hijos de Santander. (1794). Págs. 203-207.

28 C $f$ Carlo Ferraro. El FINANCIAMIENTO A LAS PYMES EN AMÉRiCA latina. Cepal. (2011). Pág. 53. 
internacionales en los que se establecen las pautas básicas de desarrollo de un proceso a manera de protección de la persona. Derecho, reconocido de igual manera en la Constitución mexicana, a través de prerrogativas mínimas que se conceden al individuo para su protección contra los actos de autoridad; reconocido como derecho humano por la por la Suprema Corte de Justicia de la Nación, la Organización de las Naciones Unidas, la Unión de Estados Americanos, la Comisión Nacional de los Derechos Humanos, entre otros.

Sin embargo, aun cuando las normas, así como los organismos citados, establecen las prerrogativas básicas para el desarrollo de procedimientos conforme a derecho, estos no son respetados en el proceso aduanal, pues sus disposiciones las viola y vulnera, sistemáticamente y de manera reiterada, la autoridad aduanera, la cual, en el ejercicio de sus funciones, no delimitadas de forma exacta, permite el ejercicio de la discresionalidad de los jueces que, de hecho, representa una violación al principio de legalidad ("los poderes públicos están sujetos a la ley") ${ }^{29}$. La falta de rigurosidad en las normas permiten que la autoridad aduanera utilice diferentes criterios para ejercer su autoridad y quedan facultados por varios ordenamientos al mismo tiempo, lo que genera violaciones a los derechos humanos y, como vimos en los supuestos analizados en el presente estudio, vulnera la garantía de audiencia-debido proceso dentro de la esfera jurídica del importador mexicano, de modo que lo deja en un estado de indefensión con respecto de los actos de autoridad que pretenden modificar.

Así se crea incertidumbre en el gobernado sobre el actuar de las autoridades aduaneras con respecto a sus facultades y limitaciones, lo que coloca al gobernado en una situación de notoria desventaja jurídica en relación con la autoridad que, al verse superada crea brechas para suplir las lagunas que se presentan y violenta, primero, su obligación de hacer solo lo que la ley le permite, para después transgredir los derechos del importador.

El derecho se crea para la sociedad a la cual va dirigido y surge de la necesidad de regular conductas. Por tanto, es necesario la reformulación, la aclaración y la delimitación de los procedimientos aduaneros, armonizándolos y haciéndolos compatibles con disposiciones que obligan a la observancia del debido proceso. Esto en razón a que, dado el estado actual

29 Véase Ricardo Guastini. Estudios de teoría constitucioNAL. Instituto de Investigaciones Jurídicas. (2001). Pág. 124. de la legislación aduanera en México, no reconoce la garantía de audiencia-debido proceso y la transgreden sistemáticamente por la falta de determinación clara y precisa de las facultades de la autoridad.

El crecimiento económico debería ser uno de los objetivos primordiales. Tanto los ordenamientos fiscales como los aduaneros deberían favorecer al sector privado a fin de fortalecer el comercio exterior (importación/exportación). Sin embargo, esto no se ha visto reflejado y, por el contrario, vemos que actualmente esta incompatibilidad del ordenamiento aduanero - con lo previsto en la Constitución a partir de la reforma en materia de derechos humanos del 10 de junio del 2011, en los instrumentos internacionales en materia de derechos humanos y en específico en lo que prevén los instrumentos internacionales de derechos económicos, sociales y culturales- solo ha reportado un descenso económico.

Los instrumentos internacionales de derechos económicos, sociales y culturales advierten crecimiento económico y protección de los derechos humanos; uno de los deberes del Estado mexicano es ser un apoyo y no un obstáculo para que el ciudadano mexicano logre su crecimiento financiero, lo cual repercute en el crecimiento económico del país.

\section{REFERENCIAS}

Adam Smith. Investigación DE LA NATURALEZA Y CAUSA DE LA RIQUEZA DE LAS NACIONES. Oficina de la viuda e Hijos de Santander. (1794).

Arturo Hoyos. Debido proceso y democracia. Porrúa. (2006)

Carlo Ferraro. El finANCiAmiento A LAS PyMES EN AMÉRiCA latina. Cepal. (2011).

Cipriano Gómez Lara. El DEBIDO PROCESO COMO DERECHO HUMANO. Instituto de Investigaciones Jurídicas.

Cipriano Gómez Lara. Teoría general Del proceso. $8^{a}$ edición. Harla. (1990).

Corte Interamericana de Derechos Humanos. CAso GeniE Lacayo, sentencia (Enero 29 de 1997). Serie C N. ${ }^{\circ}$ 21. Disponible en: http://www.corteidh.or.cr/docs/ casos/articulos/seriec_30_esp.pdf.

Comisión Nacional de los Derechos Humanos. Debido PRoceso. (2018). Disponible en http://www.cndh.org. mx/Derecho_Audiencia_Proceso_Legal.

Constitución Política de los Estados Unidos Mexicanos [Const]. Art.14. Febrero 5 de 1917. (México). 
Convención Americana de los Derechos Humanos [CADH] Art. 8. Julio 18 de 1978 (Costa Rica).

Corte Interamericana de Derechos Humanos. CAso Genie LACAyo, sentencia. (Enero 29 de 1997). Serie C N. 21. Párrafo 74. Disponible en: http://www.corteidh. or.cr/docs/casos/articulos/seriec_30_esp.pdf.

Declaración Americana de los Derechos y Deberes del Hombre [DADYDH]. Art. XVIII. Mayo 2 de 1948 (Colombia).

Declaración Universal de Derechos Humanos [DUDH]. Arts. 10. Diciembre 10 de 1948 (Francia).

Federico G. Thea. Artículo 8. Garantías judiciales. Ed. Enrique Alonso Regueira. LA CONVENCIÓN AMERICANA DE DERECHOS HUMANOS Y SU PROYECCIÓN EN EL DERECHo ARgentino. Fedye. (2013).

Gabriela Aguado Romero, Noemí Bello Gallardo y Alina del Carmen Nettel. Un espacio judicial para una teoría naturalizada de los derechos humanos. Coord. Gabriela Aguado Romero, Noemí Bello Gallardo y Alina del Carmen Nettel. Derecho administrativo. UN ÁMBITO DE RESPETO, PROMOCIÓN, PROTECCIÓN Y GARANTÍA DE LOS DEREChos humanos. Tirant lo Blanch. (2016). Pág. 45-74.
Ian Fillis. Small firm Internationalisation: an investigative survey and future research directions. JOURNAL OF MANAGEMENT DeCision 39(9). 2001. Págs. 767-783.

Juan Francisco Linares. LA RAZONABILIDAD DE LAS LEYES. $2^{a}$ edición. Astrea. (1989).

José Ovalle Favela. Teoría general Del proceso. $6^{\mathrm{a}}$ edición. Oxford. (2005). Pág. 39.

Ley Aduanera [LA] Arts. 152. Diciembre 15 de 1995 (México).

Nohemí Bello Gallardo y Luis Eusebio Alberto Avendaño González. La garantía de audiencia en algunos procedimientos aduaneros. LETRAS JURÍDICAs 31. Enero-junio. 2016.

Osvaldo Alfredo Gozaíni. El DEBIDo Proceso CONSTITUCIONAL. REgLAS PARA EL CONTROL DE LOS PODERES DESDE LA MAGISTRATURA CONSTITUCIONAL. Instituto de Investigaciones Jurídicas. (2011).

Pacto Internacional de Derechos Civiles y Políticos [PIDCYP] Art. 2.3 Marzo 23 de 1976 (EUA).

Ricardo Guastini. Estudios DE TEORÍA CONSTITUCIONAL. Instituto de Investigaciones Jurídicas. (2001).

Tesis 1a/J. 11/2014. Semanario JUdicial DE LA FederaCIÓN Y SU GACETA Décima Época, t. I. Febrero de 2014. Pág. 396. 